\title{
Resistance of Colorimetric Carbon Dioxide Detectors Commonly Utilized in Neonates
}

\author{
Melissa K Brown RRT-NPS, Danielle V Lazarus RRT, Sarah R Gonzales RRT, \\ Wade D Rich RRT-NPS CCRC, Madeline J Wozniak, Debra M Poeltler PhD, and \\ Anup C Katheria MD
}

\begin{abstract}
BACKGROUND: Colorimetric end-tidal carbon dioxide $\left(\mathrm{ETCO}_{2}\right)$ detectors can identify airway obstruction during noninvasive ventilation and successful intubation during newborn resuscitation. The resistance of these devices is not well described, and the information provided by manufacturers is incomplete. METHODS: We compared the resistance of 3 colorimetric ETCO $\mathrm{C}_{2}$ detectors (Neo-StatCO $\mathrm{C}_{2}$, Pedi-Cap, and Mini StatCO ${ }_{2}$,) and 2 mainstream capnograph sensors (EMMA infant airway adapter 17449 and neonatal/infant airway adapter YG-213T). Endotracheal tubes, 2.54.0-mm inner diameter (Portex) were measured as a reference range. A differential pressure transducer was placed between the device and a T-piece resuscitator. The other side of the device was open to air. Resistance to flow was tested at 1-10 L/min. Resistance was calculated as the change in pressure over change in flow and expressed as $\mathrm{cm} \mathrm{H}_{2} \mathrm{O} / \mathrm{L} / \mathrm{s}$. RESULTS: There was a significantly higher mean resistance across all flows tested for the Neo-StatCO $\mathrm{O}_{2}$ compared with the other $\mathrm{ETCO}_{2}$ devices $(P<.001)$. There was a 6 -fold difference between the least and most resistive colorimetric detectors. At the commonly utilized flow of $10 \mathrm{~L} / \mathrm{min}$, the resistance of the $\mathrm{Neo}-\mathrm{StatCO}$ was $61.1 \mathrm{~cm} \mathrm{H} \mathrm{H}_{2} \mathrm{O} / \mathrm{L} / \mathrm{s}$, comparable with that of a 3.0 endotracheal tube, which we measured at $62.7 \mathrm{~cm} \mathrm{H} \mathrm{H}_{2} \mathrm{O} / \mathrm{L} / \mathrm{s}$. The resistance values of the Pedi-Cap and Mini $\mathrm{StatCO}_{2}$ were 9.9 and $8.4 \mathrm{~cm}$ $\mathrm{H}_{2} \mathrm{O} / \mathrm{L} / \mathrm{s}$, respectively. Those of the EMMA and YG-213T were 7.1 and $2.6 \mathrm{~cm} \mathrm{H}_{2} \mathrm{O} / \mathrm{L} / \mathrm{s}$, respectively. CONCLUSIONS: We found significant differences in resistance between devices used to detect $\mathrm{ETCO}_{2}$ during resuscitation of premature infants. Future trials are needed to determine the effects of this resistance on work of breathing, particularly on very premature newborns receiving mask CPAP. Key words: resistance; work of breathing; continuous positive airway pressure; capnography; carbon dioxide detector; infant; newborn; neonatal intensive care; resuscitation; colorimetric. [Respir Care 2016;61(8):1003-1007. (c) 2016 Daedalus Enterprises]
\end{abstract}

\section{Introduction}

Colorimetric end-tidal carbon dioxide $\left(\mathrm{ETCO}_{2}\right)$ detectors are inexpensive, portable, lightweight, single-use devices. They have a $\mathrm{pH}$-sensitive chemical indicator, which changes color in the presence of exhaled carbon dioxide. When color change occurs, it indicates that there is both adequate ventilation and adequate blood flow circulating

The authors are affiliated with the Neonatal Research Institute, Sharp Mary Birch Hospital for Women and Newborns, San Diego, California.

Mr Rich has disclosed a relationship with Discovery Laboratories. The other authors have disclosed no conflicts of interest.

Ms Gonzales presented an abstract of this paper at the Pediatric Academic Societies Annual Meeting, held April 25-28th, 2015, in San Diego, California. through the lungs. They are the most frequently utilized $\mathrm{ETCO}_{2}$ device in the neonatal resuscitation environment and have been demonstrated to be effective in determining successful endotracheal intubation. ${ }^{1,2}$ We have shown that colorimetric $\mathrm{ETCO}_{2}$ detectors are also effective in recognizing airway obstruction, with bag-mask ventilation or CPAP application, during delivery room resuscitation of premature infants. ${ }^{3}$ At the time of these findings, we utilized a detector that was labeled for use in infants $>1 \mathrm{~kg}$. Since that time, a detector has been approved for infants $<1$

Correspondence: Melissa K Brown RRT-NPS, Neonatal Research Institute, Sharp Mary Birch Hospital for Women and Newborns, 3003 Health Center Drive, San Diego, CA 92123. E-mail: melissa.brown@sharp.com.

DOI: $10.4187 /$ respcare. 04507 
$\mathrm{kg}$ that has a reduced dead space. There are no published data on the resistance of this newer device with the flows commonly utilized clinically, 6-10 L/min. Because colorimetric $\mathrm{ETCO}_{2}$ detectors have historically been used to determine the success of intubation, which can be done in just a few breaths, little attention has been paid to their resistance profile.

\section{See the Related Editorial on Page 1129}

It has long been accepted that the resistance of the endotracheal tube (ETT) is a factor in gas exchange and the work of breathing in neonatal patients. ${ }^{4,5}$ The filling and emptying of the lung is dependent on the time constant (airway resistance $\times$ respiratory system compliance). Imposed resistance through any or all airways can lead to ventilation-perfusion mismatch, increased work of breathing, ineffective gas exchange, and hyperinflation. ${ }^{6}$

The purpose of this study was to test colorimetric $\mathrm{ETCO}_{2}$ detectors to determine their resistance, which would play an important role in their use over a longer period of time in spontaneously breathing infants.

\section{Methods}

We compared the resistance of 3 colorimetric $\mathrm{ETCO}_{2}$

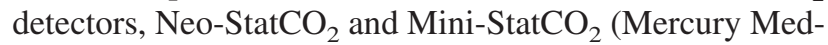
ical, Clearwater, Florida) and Pedi-Cap (Covidien, Mansfield, Massachusetts), and 2 mainstream capnograph sensors, the EMMA infant airway adapter 17449, a portable $\mathrm{ETCO}_{2}$ sensor (Masimo Corporation, Irvine, California) and the neonatal/infant airway adapter YG-213T (Nihon Kohden America, Foothill Ranch, California). Four standard Portex neonatal ETTs, size 2.5-4.0-mm inner diameter (Smiths Medical, Hythe, United Kingdom), which were cut to a length appropriate for clinical use, were also tested to help establish a reference range. The manufacturer's specifications for the $\mathrm{ETCO}_{2}$ devices can be found in Figure 1. Three samples of each $\mathrm{ETCO}_{2}$ detector were tested and compared. The devices were placed in a flow circuit distal to the transducer with the opposite end of the device open to air (Fig. 2). All 3 samples of each device were tested once at flows of 1-10 L/min in 1-L increments of dry, room temperature air, using a flow meter (Precision Medical, Northampton, Pennsylvania). The flow meter has an accuracy of $\pm 0.5 \mathrm{~L} / \mathrm{m}$ from 0 to $5 \mathrm{~L} / \mathrm{min}$ and $\pm 1.0 \mathrm{~L} / \mathrm{min}$ from 5 to $15 \mathrm{~L} / \mathrm{min}$. The flow meter was not calibrated because flow was set before each run and was constant across all measurements. Hence, the accuracy of the flow signal was not critical to the findings. Three measurements were taken of proximal airway pressure, one from each of the 3 device samples, and the resistance was calculated as the change in pressure over the change in flow divided by 60 and expressed as $\mathrm{cm}$ $\mathrm{H}_{2} \mathrm{O} / \mathrm{L} / \mathrm{s}$. Pressure was measured using a differential pressure transducer and a universal interface module attached to an

\section{QUICK LOOK}

\section{Current knowledge}

Previous studies have demonstrated that colorimetric $\mathrm{ETCO}_{2}$ detectors are helpful in confirming successful endotracheal intubation. Current practice is evolving to also utilize these devices during neonatal resuscitation with a mask interface. Colorimetric $\mathrm{ETCO}_{2}$ detectors are effective at identifying airway obstruction in spontaneously breathing premature neonates. One device, the $\mathrm{Neo}-\mathrm{StatCO}_{2}$, is labeled for neonates $<1 \mathrm{~kg}$, but the resistance in the normal operating range is not available in publications or the product literature.

\section{What this paper contributes to our knowledge}

In an in vitro model, the Neo-StatCO $\mathrm{CO}_{2}$ had a significantly greater resistance than 2 other colorimetric $\mathrm{ETCO}_{2}$ detectors used in neonatal resuscitation. The resistance of the Neo-StatCO $\mathrm{ETCO}_{2}$ detector was comparable with that of a $3.0 \mathrm{ETT}$.

MP150 data acquisition system (Biopac Systems, Goleta, California). The TSD-160C transducer is a $\pm 25 \mathrm{~cm} \mathrm{H}_{2} \mathrm{O}$ differential transducer, with accuracy of $\pm 0.5 \%$. A 2-point calibration was done at 0 and $20 \mathrm{~cm} \mathrm{H}_{2} \mathrm{O}$ before recording. All data were sampled at $200 \mathrm{~Hz}$. Post-collection analysis was completed using the accompanying Acqknowledge software.

\section{Data Analysis}

Data are expressed as mean \pm SD. Data analyses were performed using SPSS 22.0 for Windows (IBM, Armonk, New York). The level of statistical significance was established a priori as $P<.05$. Descriptive analyses were used to evaluate frequencies and distributions of variables and potential outlier values. Scatterplots were examined to evaluate assumptions of normality, linearity, and homogeneity of variance. The mean and median values were comparable at each level and consistency among standard deviations, suggesting the use of parametric methods for subsequent analyses. Additional post hoc confirmation regarding appropriate use of the measure of central tendency for the 3 values was conducted using non-parametric testing (Kruskall-Wallis and median tests), and these tests led to similar statistical conclusions regarding acceptance or rejection of null hypotheses. Twotailed Student $t$ tests were used to compare the overall mean values obtained for each device as compared with the Neo$\mathrm{StatCO}_{2}$ device. Repeated measures analysis of variance was used to test whether the means obtained at the 10 observations of the 5 devices were equal. Bonferroni post hoc adjustment was used to reduce the likelihood of type-1 error. 


\begin{tabular}{|c|c|c|c|c|c|}
\hline Device & Pedi-Cap & Mini StatCO ${ }_{2}$ & Neo-StatCO $\mathrm{C}_{2}$ & $\begin{array}{l}\text { Nihon Kohden } \\
\text { YG-213T }\end{array}$ & $\begin{array}{l}\text { EMMA } \\
\text { Infant Airway } \\
\text { Adapter } 17449\end{array}$ \\
\hline Dead space & $3 \mathrm{~mL}$ & $3 \mathrm{~mL}$ & $1 \mathrm{~mL}$ & $1.8 \mathrm{~mL}$ & $1 \mathrm{~mL}$ \\
\hline Lifespan & $2 \mathrm{~h}$ & $24 \mathrm{~h}$ & $24 \mathrm{~h}$ & $72 \mathrm{~h}$ & $12 \mathrm{~h}$ \\
\hline $\begin{array}{l}\text { Resistance to } \\
\text { flow }\end{array}$ & $\begin{array}{l}2.5 \mathrm{~cm} \mathrm{H}_{2} \mathrm{O} \pm \\
0.5 \mathrm{~cm} \mathrm{H}_{2} \mathrm{O} \text { at } \\
10 \mathrm{~L} / \mathrm{min}^{2}\end{array}$ & $\begin{array}{l}2.5 \mathrm{~cm} \mathrm{H}_{2} \mathrm{O} \text { at } \\
10 \mathrm{~L} / \mathrm{min}\end{array}$ & $\begin{array}{l}3 \mathrm{~cm} \mathrm{H}_{2} \mathrm{O} \text { at } \\
5 \mathrm{~L} / \mathrm{min}^{*}\end{array}$ & $\begin{array}{l}0.8 \mathrm{~cm} \mathrm{H}_{2} \mathrm{O} \text { at } \\
10 \mathrm{~L} / \mathrm{min}\end{array}$ & $\begin{array}{l}1 \mathrm{~cm} \mathrm{H}_{2} \mathrm{O} \text { at } \\
10 \mathrm{~L} / \mathrm{min}\end{array}$ \\
\hline $\begin{array}{l}\text { Current } \\
\text { labeling }\end{array}$ & $1-15 \mathrm{~kg}$ & $1-15 \mathrm{~kg}$ & $0.25-6 \mathrm{~kg}$ & $2.0-7 \mathrm{~kg}$ & $<10 \mathrm{~kg}$ \\
\hline
\end{tabular}

Fig. 1. Manufacturer's specifications of the 5 neonatal $\mathrm{ETCO}_{2}$ devices. ${ }^{*} 10 \mathrm{~L} / \mathrm{min}$ data not available.

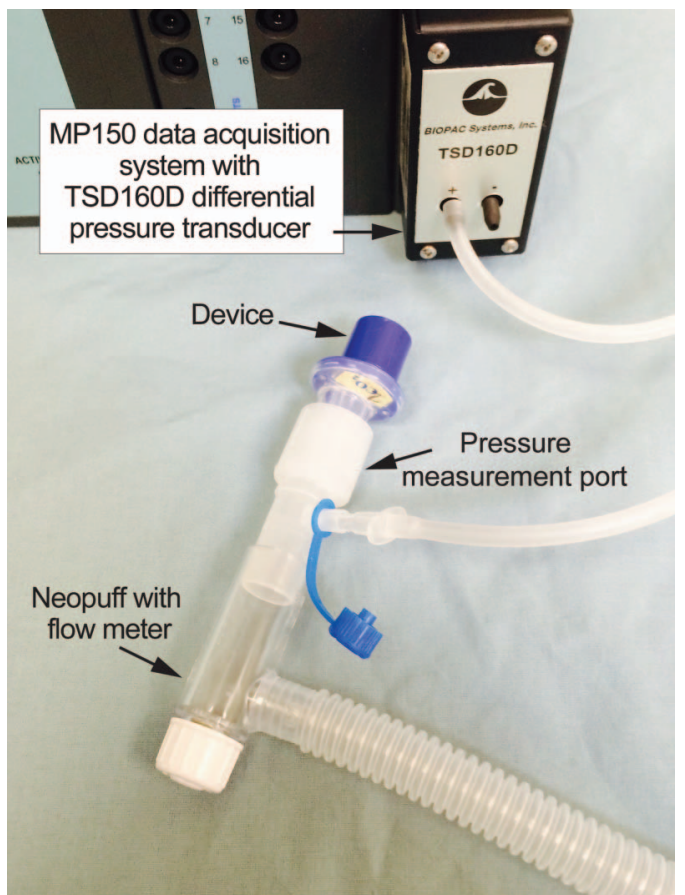

Fig. 2. Experiment setup.

\section{Results}

The mean $\pm \mathrm{SD}$ values of all $\mathrm{ETCO}_{2}$ devices across all flows are provided in Table 1 . The mean resistance of the Neo-StatCO $\mathrm{C}_{2}$ compared with the other 4 devices was different $(P<.001)$, and these differences persisted at variable flows $(1-10 \mathrm{~L} / \mathrm{min})$. These differences also persisted $(P<.001)$ after adjusting for each flow rate by repeated measures analysis of variance.

We found that the Neo-StatCO $\mathrm{C}_{2}$ had the greatest resistance of all of the $\mathrm{ETCO}_{2}$ devices tested. At the commonly utilized flow of $10 \mathrm{~L} / \mathrm{min}$, the resistance of the $\mathrm{Neo}-\mathrm{StatCO}_{2}$ was $61.1 \mathrm{~cm} \mathrm{H}_{2} \mathrm{O} / \mathrm{L} / \mathrm{s}$, comparable with that of a $3.0 \mathrm{ETT}$, which we measured at $62.7 \mathrm{~cm} \mathrm{H}_{2} \mathrm{O} / \mathrm{L} / \mathrm{s}$. The Neo-StatCO detector had approximately 5-6 times greater resistance to air flow, on average across all flows, than the other 2 calorimetric $\mathrm{ETCO}_{2}$ detectors. It had approximately 8 times the resistance of the EMMA airway adapter and 22 times the resistance of the Nihon Kohden airway adapter. As flow increased, so did resistance for all of the devices tested (Fig. 3).

\section{Discussion}

Colorimetric $\mathrm{ETCO}_{2}$ detectors are primarily used to recognize whether an ETT is accurately placed. Current practice is evolving to also utilize these devices with a mask interface during CPAP. Although the effects of artificial airways on spontaneous breathing during mechanical ventilation are well studied, their effects on work of breathing during bag mask ventilation or applied CPAP are not. ${ }^{7} \mathrm{Re}-$ sistance to flow is a critical factor when providing ventilation or CPAP to the spontaneously breathing infant. Imposed work of breathing can occur when a patient must breathe spontaneously through an artificial apparatus placed between the lungs and the air, such as ETTs, ETCO 2 detectors, flow sensors, and expiratory valves. ${ }^{6}$ With an increase in the work of breathing, a neonate may experience diaphragmatic fatigue, apnea, and respiratory failure. 8,9 The resistance profiles of neonatal ETTs are well documented, and as a result, ETT CPAP is not routinely performed in neonates. ${ }^{4,5,10}$ One of the devices we measured, if used in a non-intubated infant, may cause similar imposed work of breathing as if the infant were intubated with a 3.0-mm ETT and breathing spontaneously.

A colorimetric $\mathrm{ETCO}_{2}$ detector can be a valuable tool to assist the clinician with identifying when the airway is not patent and airway repositioning is necessary. However, for color change to occur on a colorimetric $\mathrm{ETCO}_{2}$ detector, the infant's exhaled gas must be in contact with the $\mathrm{CO}_{2}$-sensitive paper for a sufficient amount of time. This is done by either creating a longer very shallow path through which gas must flow, as in the Pedi-Cap, or by passing the gas through

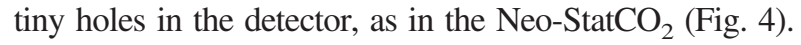


Table 1. Mean Resistance Expressed as $\mathrm{cm} \mathrm{H}_{2} \mathrm{O} / \mathrm{L} / \mathrm{s}$ of Colorimetric $\mathrm{ETCO}_{2}$ Detectors and Airway Adapters in 1-L Increments of Flow $1-10 \mathrm{~L} / \mathrm{min}$

\begin{tabular}{|c|c|c|c|c|c|c|c|c|c|c|c|}
\hline \multirow{2}{*}{ Device } & \multicolumn{11}{|c|}{ Mean Resistance, $\mathrm{cm} \mathrm{H}_{2} \mathrm{O} / \mathrm{L} / \mathrm{s}$} \\
\hline & $1 \mathrm{~L} / \mathrm{min}$ & $2 \mathrm{~L} / \mathrm{min}$ & $3 \mathrm{~L} / \mathrm{min}$ & $4 \mathrm{~L} / \mathrm{min}$ & $5 \mathrm{~L} / \mathrm{min}$ & $6 \mathrm{~L} / \mathrm{min}$ & $7 \mathrm{~L} / \mathrm{min}$ & $8 \mathrm{~L} / \mathrm{min}$ & $9 \mathrm{~L} / \mathrm{min}$ & $10 \mathrm{~L} / \mathrm{min}$ & $1-10 \mathrm{~L} / \mathrm{min}$ \\
\hline $\mathrm{Neo}-\mathrm{StatCO}_{2}$ & $18.0 \pm 0.9$ & $20.6 \pm 1.0$ & $25.4 \pm 1.3$ & $27.8 \pm 1.4$ & $31.1 \pm 1.6$ & $34.9 \pm 1.8$ & $41.7 \pm 2.1$ & $47.5 \pm 2.4$ & $54.1 \pm 2.7$ & $61.1 \pm 3.1$ & $36.2 \pm 14.5$ \\
\hline Pedi-Cap & $5.1 \pm 0.2$ & $5.3 \pm 0.2$ & $5.9 \pm 0.3$ & $6.2 \pm 0.3$ & $6.6 \pm 0.3$ & $7.0 \pm 0.3$ & $8.0 \pm 0.4$ & $8.5 \pm 0.4$ & $9.2 \pm 0.4$ & $9.9 \pm 0.4$ & $7.1 \pm 1.7$ \\
\hline Mini $\mathrm{StatCO}_{2}$ & $4.2 \pm 0.2$ & $4.4 \pm 0.2$ & $4.8 \pm 0.3$ & $4.9 \pm 0.3$ & $5.6 \pm 0.3$ & $5.9 \pm 0.3$ & $6.6 \pm 0.4$ & $7.2 \pm 0.4$ & $7.8 \pm 0.4$ & $8.4 \pm 0.5$ & $6.0 \pm 1.5$ \\
\hline $\begin{array}{l}\text { EMMA airway } \\
\text { adapter }\end{array}$ & $2.5 \pm 0.07$ & $2.6 \pm 0.07$ & $3.0 \pm 0.1$ & $3.1 \pm 0.1$ & $3.4 \pm 0.1$ & $4.9 \pm 0.1$ & $5.3 \pm 0.2$ & $6.0 \pm 0.2$ & $6.7 \pm 0.2$ & $7.1 \pm 0.2$ & $4.5 \pm 1.7$ \\
\hline Nihon Kohden & $0.8 \pm 0.02$ & $0.9 \pm 0.03$ & $1.0 \pm 0.0$ & $1.2 \pm 0.0$ & $1.4 \pm 0.0$ & $1.6 \pm 0.1$ & $1.8 \pm 0.1$ & $2.1 \pm 0.0$ & $2.4 \pm 0.1$ & $2.6 \pm 0.1$ & $1.6 \pm 0.6$ \\
\hline
\end{tabular}

$\overline{\text { Results are mean } \pm \text { SD }}$ resistance across all flows of $1-10 \mathrm{~L} / \mathrm{min}$

All results were significant $(P<.001)$ as compared to the Neo-Stat $\mathrm{CO}_{2}$

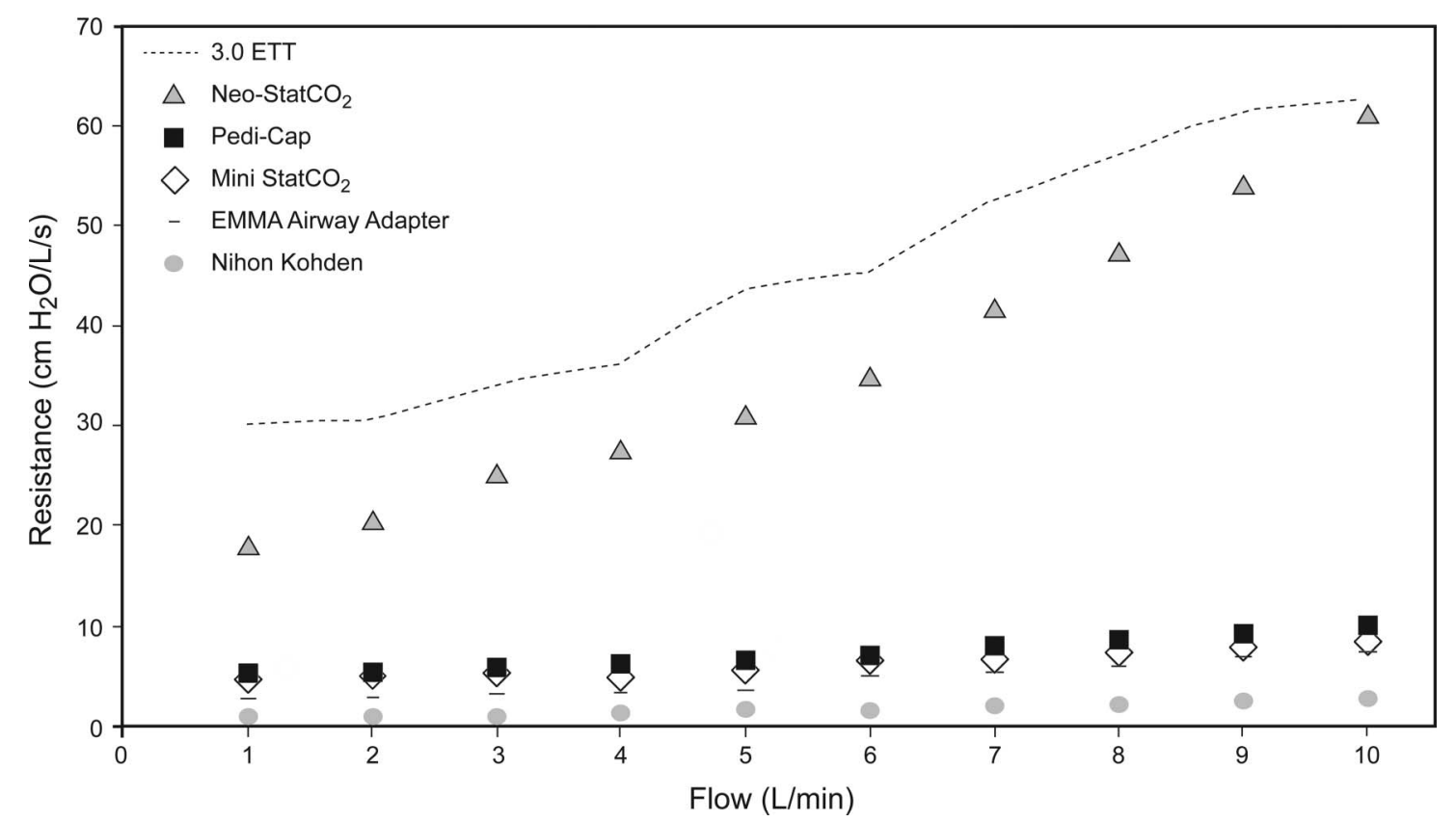

Fig. 3. The mean resistance expressed in $\mathrm{cm} \mathrm{H}_{2} \mathrm{O} / \mathrm{L} / \mathrm{s}$ of the 5 neonatal $\mathrm{ETCO}_{2}$ devices and a $3.0 \mathrm{ETT}$ relative to flows of $1-10 \mathrm{~L} / \mathrm{min}$. The mean resistance of the Neo-StatCO $\mathrm{C}_{2}$ is significantly greater those that of the other $4 \mathrm{ETCO}_{2}$ devices, $P<.001$.

In addition to enough contact time, adequate tidal volume is necessary to create a recognizable color change in colorimetric $\mathrm{ETCO}_{2}$ detectors. A device with a larger dead space volume may require larger tidal volumes to show a color change than one with a smaller dead space. Small volumes may get washed out in the dead space of the device, producing a false negative result.1,11 The Neo$\mathrm{StatCO}_{2}$ is the first colorimetric detector labeled for infants $<1 \mathrm{~kg}$. The product literature from the manufacturer on the resistance of this new detector is limited to $5 \mathrm{~L} / \mathrm{min}$. We compared the Neo-StatCO $\mathrm{C}_{2}$ with other colorimetric $\mathrm{ETCO}_{2}$ devices in the flow range in which they are most widely utilized, $6-10 \mathrm{~L} / \mathrm{min}$. To our knowledge, there are no prior publications validating the manufacturer's specifications (Fig. 1). The dead space has been decreased and the

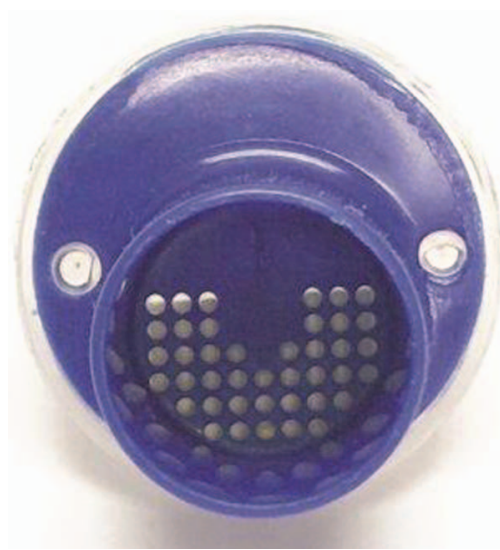

Fig. 4. On-end view of the tiny holes gas travels through in the $\mathrm{Neo}-\mathrm{Stat} \mathrm{CO}_{2} \mathrm{ETCO}_{2}$ detector. 
resistance to flow has increased in the Neo-StatCO $\mathrm{CO}_{2}$ compared with the Mini $\mathrm{StatCO}_{2}$. There are no studies demonstrating that these design changes have improved the sensitivity to the presence of $\mathrm{ETCO}_{2}$, improved response time, or decreased the possibility of a false negative reading.

We previously studied both the Pedi-Cap and the Mini Stat $\mathrm{CO}_{2}$ in an artificial lung model to determine the minimal tidal volume necessary to generate a color change. ${ }^{12}$ The Mini $\mathrm{StatCO}_{2}$ tidal volume threshold was $0.83 \mathrm{~mL}$, and the Pedi-Cap tidal volume threshold was $1.08 \mathrm{~mL}$, both amply sensitive for the expected tidal volume of a $400-\mathrm{g}$ infant. Both detectors are appropriate for use with any premature neonate. In another study of 45 neonates, 19 subjects were $<1 \mathrm{~kg}$; the Pedi-Cap correctly identified 18 tracheal intubations with only one false negative. The authors recommended the Pedi-Cap for all neonates, including babies $<1 \mathrm{~kg} .{ }^{13}$ All 3 of the false negatives in the overall study population had Apgar scores of $<2$ or cardiac arrest. $\mathrm{ETCO}_{2}$ detectors are susceptible to false negative readings secondary to inadequate circulation as well as false positive readings due to contact with medications such as epinephrine. ${ }^{13-15}$

There are currently no recommendations for any one method of $\mathrm{ETCO}_{2}$ monitoring for neonates. ${ }^{14}$ There are limited data regarding the perceived benefits of one colorimetric $\mathrm{ETCO}_{2}$ device over another. Hawkes et al ${ }^{16}$ found that two thirds of neonatal and pediatric trainees preferred the Neo-StatCO $\mathrm{C}_{2}$ because of its horizontal positioning, but they also felt that the visual indicator was smaller and more frequently covered by the hand of the operator when compared with the Pedi-Cap. They found no significant differences in efficacy between devices.

Our study was an in vitro design, and as such we did not test our devices on spontaneously breathing newborns. Further testing in the clinical environment will be helpful in determining the exact effect of these high-resistance devices in the spontaneously breathing neonate.

\section{Conclusion}

Detection of $\mathrm{ETCO}_{2}$ in newborns after delivery has been critical for advancing resuscitative techniques and improving the efficiency of responses to airway emergencies. We have found that some detectors have significant resistance, equivalent to ETTs. It is important for clinicians to recognize the increased resistance caused by $\mathrm{ETCO}_{2}$ detectors and to discontinue their use when they are no longer required. Clinicians also need to be aware that there is potential impact on work of breathing from utilizing $\mathrm{ETCO}_{2}$ detectors in spontaneously breathing newborns on mask CPAP. Future trials are needed to determine the effects of this resistance on work of breathing, particularly on very premature newborns receiving mask CPAP.

\section{REFERENCES}

1. Bhende MS, Thompson AE, Orr RA. Utility of an end-tidal carbon dioxide detector during stabilization and transport of critically ill children. Pediatrics 1992;89(6 Pt 1):1042-1044.

2. Bhende MS, Thompson AE. Evaluation of an end-tidal $\mathrm{CO}_{2}$ detector during pediatric cardiopulmonary resuscitation. Pediatrics 1995; 95(3):395-399.

3. Finer NN, Rich W, Wang C, Leone T. Airway obstruction during mask ventilation of very low birth weight infants during neonatal resuscitation. Pediatrics 2009;123(3):865-869.

4. LeSouef PN, England SJ, Bryan AC. Total resistance of the respiratory system in preterm infants with and without an endotracheal tube. J Pediatr 1984;104(1):108-111.

5. Oca MJ, Becker MA, Dechert RE, Donn SM. Relationship of neonatal endotracheal tube size and airway resistance. Respir Care 2002; 47(9):994-997.

6. DiBlasi RM, Salyer JW, Zignego JC, Redding GJ, Richardson CP. The impact of imposed expiratory resistance in neonatal mechanical ventilation: a laboratory evaluation. Respir Care 2008;53(11):1450-1460.

7. Manczur T, Greenough A, Nicholson GP, Rafferty GF. Resistance of pediatric and neonatal endotracheal tubes: influence of flow rate, size, and shape. Crit Care Med 2000;28(5):1595-1598.

8. Lopes JM, Muller NL, Bryan MH, Bryan AC. Synergistic behavior of inspiratory muscles after diaphragmatic fatigue in the newborn. J Appl Physiol Respir Environ Exerc Physiol 1981;51(3):547-551.

9. Wall MA. Infant endotracheal tube resistance: effects of changing length, diameter, and gas density. Crit Care Med 1980;8(1):38-40.

10. Brown ES. Resistance factors in pediatric endotracheal tubes and connectors. Anesth Analg 1971;50(3):355-360.

11. Molloy EJ, Deakins K. Are carbon dioxide detectors useful in neonates? Arch Dis Child Fetal Neonatal Ed 2006;91(4):F295-F298.

12. Garey DM, Ward R, Rich W, Heldt G, Leone T, Finer NN. Tidal volume threshold for colorimetric carbon dioxide detectors available for use in neonates. Pediatrics 2008;121(6):e1524-e1527.

13. Aziz HF, Martin JB, Moore JJ. The pediatric disposable end-tidal carbon dioxide detector role in endotracheal intubation in newborns. J Perinatol 1999;19(2):110-113.

14. Perlman JM, Wyllie J, Kattwinkel J, Atkins DL, Chameides L, Goldsmith JP, et al. Part 11: neonatal resuscitation: 2010 international consensus on cardiopulmonary resuscitation and emergency cardiovascular care science with treatment recommendations. Circulation 2010;122(16 Suppl 2):S516-S538.

15. Hughes SM, Blake BL, Woods SL, Lehmann CU. False-positive results on colorimetric carbon dioxide analysis in neonatal resuscitation: potential for serious patient harm. J Perinatol 2007;27(12):800-801.

16. Hawkes GA, O'Connell BJ, Livingstone V, Hawkes CP, Ryan CA, Dempsey EM. Efficacy and user preference of two $\mathrm{CO}_{2}$ detectors in an infant mannequin randomized crossover trial. Eur J Pediatr 2013;172(10):1393-1399.

This article is approved for Continuing Respiratory Care Education credit. For information and to obtain your CRCE

(free to AARC members) visit

www.rcjournal.com

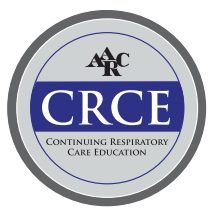

